\title{
RARE CASE OF MALIGNANT PROLIFERATING TRICHILEMMAL TUMOUR
}

Poorna Shetti', Swapna Athawale², Nikhil Talathi' ${ }^{3}$, Hemant Lekawale 4

12nd Year Postgraduate Resident, Department of General Surgery, SKNMC and GH, Pune, Maharashtra, India. ${ }^{2}$ Assistant Professor, Department of Plastic Surgery, SKNMC and GH, Pune, Maharashtra, India. ${ }_{3}^{3}$ Assistant Professor (Neuro Surgeon), Department of Neurosurgery, SKNMC and GH, Pune, Maharashtra, India. 4 Professor (Onco Surgeon), Department of Onco Surgery, SKNMC and GH, Pune, Maharashtra, India.

HOW TO CITE THIS ARTICLE: Shetti P, Athawale S, Talathi N, et al. Rare case of malignant proliferating trichilemmal tumour. J. Evolution Med. Dent. Sci. 2018;7(41):5278-5280, DOI: 10.14260/jemds/2018/998

\section{PRESENTATION OF CASE}

- A 45 years old female patient came with c/o non-healing ulcer over left occipital region since a year.

- $\quad$ She gave history of being operated thrice for nodular growth over occipital region, which recurred after two surgeries and after the third surgery she developed an ulcer.

- The three surgeries took place in 2015- Satara, May 2016- Phaltan and in Dec 2016- Phaltan.

- CT brain was done during all these surgeries, which revealed no intracranial abnormality or involvement of cranial vault.

- HPE done after surgery in May 2016 was s/o Epidermoid tumour/ infected sebaceous cyst in the subgaleal region.

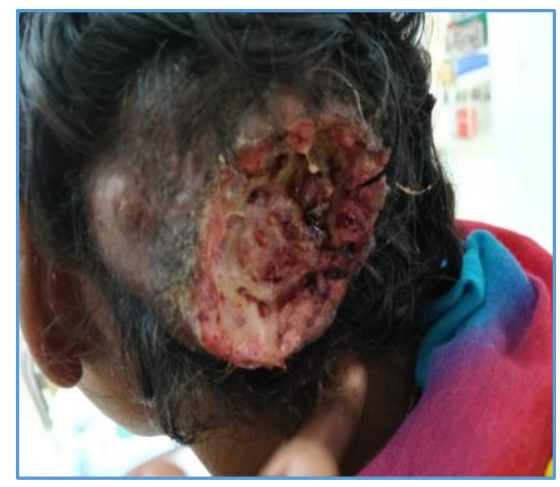

Presentation in Casualty

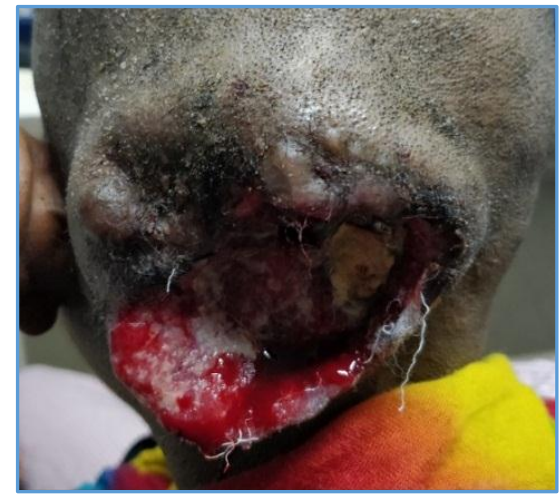

Preoperative Presentation

'Financial or Other Competing Interest': None.

Submission 18-08-2018, Peer Review 21-09-2018,

Acceptance 27-09-2018, Published 08-10-2018.

Corresponding Author:

Dr. Poorna Shetti,

B-2003, Kandivali Kesar Ashish CHSL,

Link Road, Mahavir Nagar, Near Vasant Complex,

Kandivali-West, Mumbai-400067, Maharashtra, India.

E-mail: poornashetti@gmail.com

DOI: $10.14260 /$ jemds $/ 2018 / 998$

(c) $(1)$
- Local Examination- An 8 x 11 x $1 \mathrm{~cm}$ ulcer was seen in left occipital region which was irregular in shape, covered with granulation tissue and slough.

- The ulcer edge was sloping and ulcer bed bled on touch.

- A single firm mobile non-tender cervical lymph node (Level 2) was palpable $3 \times 2 \times 1 \mathrm{~cm}$ on the left side.

\section{DIFFERENTIAL DIAGNOSES}

- Cutaneous squamous cell carcinoma.

- Sebaceous carcinoma.

- Clear cell hidradenocarcinoma.

- Cutaneous metastasis of RCC.

- Cylindroma.

- Dermoid cyst.

- $\quad$ Epidermal inclusion cyst.[1]

\section{CLINICAL DIAGNOSIS}

Patient underwent routine lab investigations, four quadrant biopsy of occipital lesion and MRI brain after being admitted in our hospital in Dec 2017.

- HPE of biopsy was s/o malignant proliferating trichilemmal tumour.

- $\quad$ MRI brain- ill-defined heterogeneously enhancing lesion in left occipital region invading underlying bone and dura.

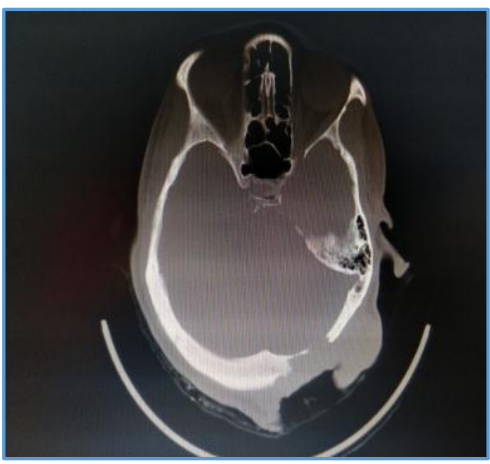

CT (Brain) s/o Breach in Bone

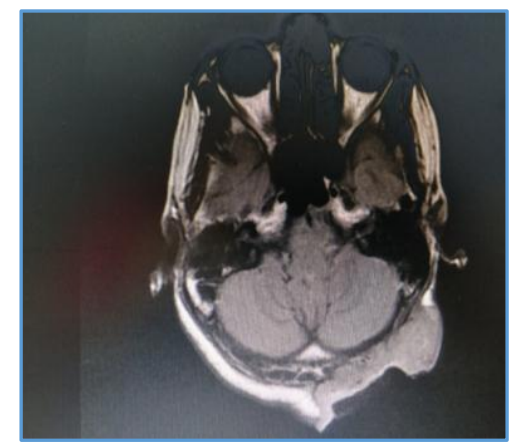

MRI (Brain) s/o Intracranial Extension 


\section{DISCUSSION OF MANAGEMENT}

Preoperative workup was done and patient was prepared for surgery and decision was taken to operate the patient by oncosurgeon, neurosurgeon and plastic surgeon-

- Firstly, oncosurgeon did WLE of occipital lesion with $2 \mathrm{~cm}$ margin and left level 2, 3, 4, 5 neck lymph node dissection.

- Then neurosurgeon removed the involved underlying bone of approx. $6 \times 5 \mathrm{~cm}$ and dura $2 \times 1 \mathrm{~cm}$.

- Then plastic surgeon harvested tensor fascia lata graft and pedicled trapezius flap $15 \times 10 \times 1 \mathrm{~cm}$.

- The dural defect was covered with tensor fascia lata graft.

- The occipital defect was covered with trapezius flap with transverse cervicalis artery pedicle after creating a tunnel below the skin and rotating it.

- The defect which developed on the donor site of trapezius flap was covered with STSG from right thigh.

- Vascularity of trapezius flap was checked.

- $\quad$ Three drains were kept in the neck region, trapezius flap region and occipital region above dura.

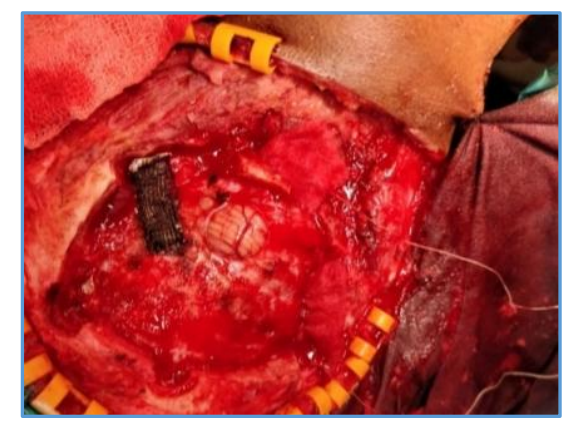

Intraoperative finding- involved Dura removed-Brain Tissue seen Bulging from Below

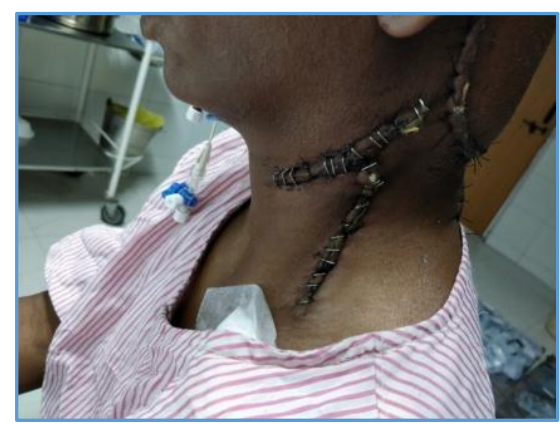

Postoperatively-Neck Lymph Node Dissection

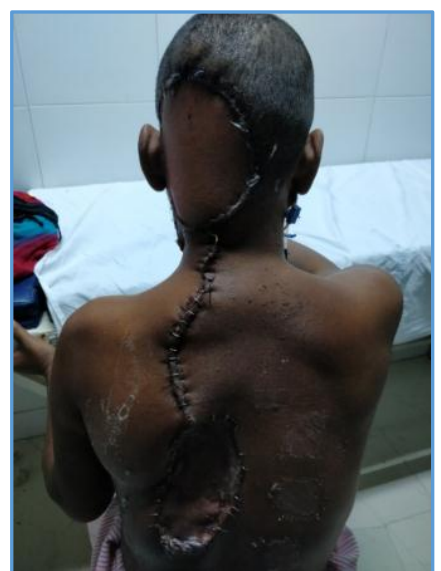

Wide Local Excision-Trapezius Flap
- 4 specimens were sent for HPE-neck dissection, WLE tumour, occipital bone, dura.

- Patient was given antibiotics for 7 days and check dressing of skin graft was done on POD 5 - 100\% graft take was there.

- $\quad$ All three drains were removed on POD 10.

- Patient complained of headache and fever on POD 15, USG revealed loculated collection of approx. $8 \times 1.6 \mathrm{~cm}$ IV antibiotics and acetazolamide tablets were given for the same for 5 days as advised by neurosurgeon.

- Follow-up- Patient was followed up every month. Patient had no e/o recurrence.

- $\quad$ Suture site was well.

- Patient had not started radiotherapy.

- Patient was counselled for radiotherapy and sent to higher centre for the same.

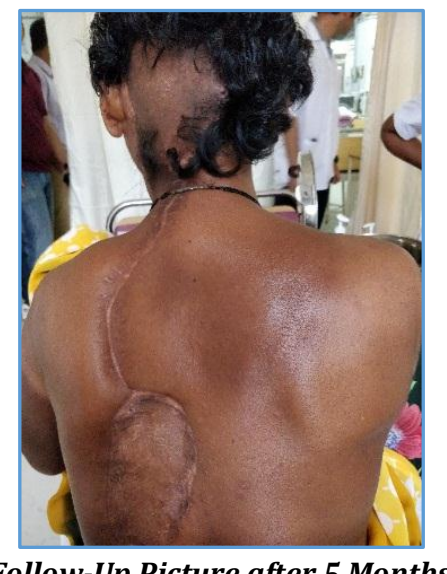

\section{PATHOLOGICAL DISCUSSION}

Histopathologically, WLE specimen s/o- Malignant proliferating trichilemmal tumour- all margins free of tumour.

- 3 out of 19 neck lymph nodes dissected showed tumour deposits.

- $\quad$ Bone and dura showed tumour deposits.

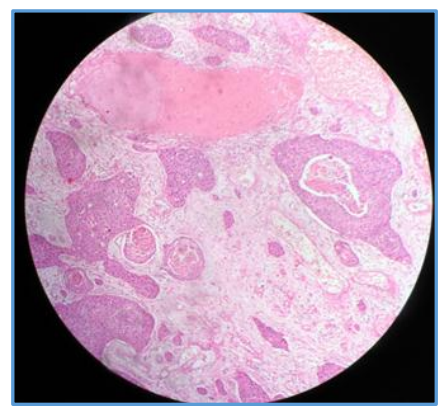

Abrupt Keratinisation

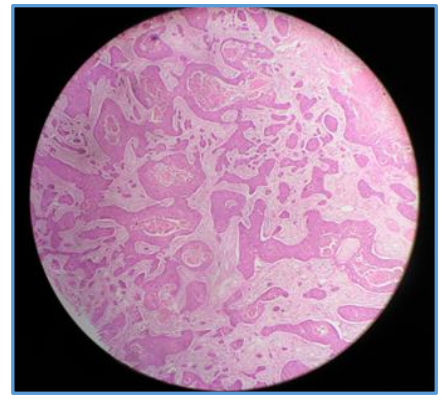

Cords and Nests Appearance 
- IHC-CD 34-negative, Calretinin-positive, p53-70\% positive, Ki67-70\% positive.

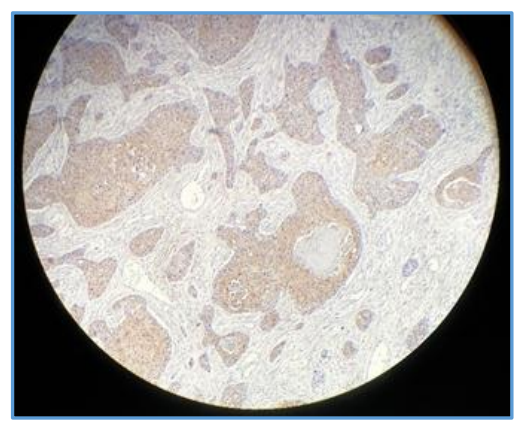

Calretinin

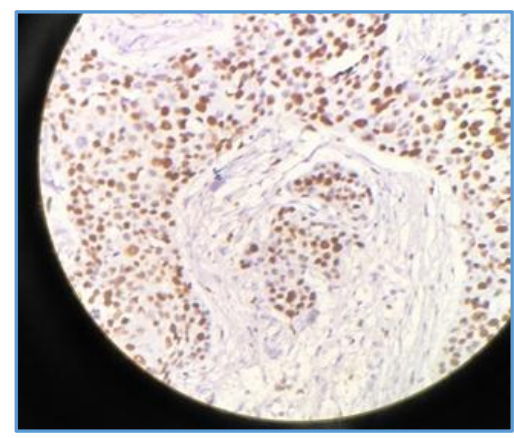

P53

- Calretinin was done to differentiate it from squamous cell carcinoma, which is the most common differential. Calretinin is never positive in SCC.

\section{FINAL DIAGNOSIS}

Proliferating Trichilemmal Tumour (PTT)

It is a tumour originating from the isthmus of the outer root sheath of a hair follicle-

- It is also commonly called a proliferating trichilemmal cyst or less commonly proliferating follicular-cystic neoplasm. It was first described by Wilson-Jones.[2]

- The usual clinical presentation of PTT is that of a long standing, subcutaneous, cystic nodule that slowly progresses to a large nodular mass.

- Ye et al[3] proposed three groups of PTT-

- Group 1- Benign lesions that are non-recurrent display well-circumscribed margins, modest nuclear atypia and no pathological mitoses-

- Group 2- Low-grade malignant lesions (locally aggressive) that may recur, exhibit irregular and locally invasive margins and involvement of deep dermis and subcutis.

- Group 3- High-grade malignant tumours with a tendency towards recurrence and lymph node metastasis, invasive pattern of growth, prominent nuclear pleomorphism, atypical mitosis, necrosis and possible vascular and neural invasion.

- Malignant transformation in such a tumour is very rare, evidenced by regional or distant metastasis, ${ }^{[4]}$ unusual finding (only 39 cases have been documented in the English language literature till date).[5]
- It is affecting the scalp of elderly women.[6] It is a large, solitary, multilobulated lesion that may arise within a trichilemmal cyst (Pilar cyst). It yields lobulated and variably exophytic masses that occasionally ulcerate.[7]

- Malignant transformation occurs occasionally, which can be manifested by sudden rapid growth. Histologically, malignant PTTs show severe nuclear atypia, marked cellular pleomorphism with atypical mitoses, dyskeratotic cells and infiltrating margins. $[8,9]$

- Malignant transformation in such a tumour was introduced by Saida et al,[10] who suggested three stages in the oncological development- adenomatous stage, epitheliomatous stage and carcinomatous stage.

- There are two growth patterns seen in malignant proliferating trichilemmal tumour-circumscribed nodular and diffuse spindle cell type.

- It is usually confused with squamous cell carcinoma.

- It is more common in females and in older individuals 50-75 years old.

- It is a chemo-resistant tumour.

\section{REFERENCES}

[1] Siddha M, Budrukkar A, Shet T, et al. Malignant pilar tumour of the scalp: a case report and review of literature. J Cancer Res Ther 2007;3(4):240-3.

[2] Jones EW. Proliferating epidermoid cysts. Arch Dermatol 1966;94(1):11-9.

[3] Ye J, Nappi O, Swanson PE, et al. Proliferating pilar tumours: a clinicopathologic study of 76 cases with a proposal for definition of benign and malignant variants. Am J Clin Pathol 2004;122(4):566-74.

[4] Park BS, Yang SG, Cho KH. Malignant proliferating trichilemmal tumor showing distant metastases. Am J Dermatopathol 1997;19(5):536-9.

[5] Garg PK, Dangi A, Khurana N, et al. Malignant proliferating trichilemmal cyst: a case report with review of literature. Malaysian J Pathol 2009;31(1):716.

[6] Rao S, Ramakrishnan R, Kamakshi D, et al. Malignant proliferating trichilemmal tumour presenting early in life: an uncommon feature. J Cutan Aesthet Surg 2011;4(1):51-5.

[7] Wick MR, Swanson PE. Cutaneous adnexal tumours: a guide to pathologic diagnosis. Chicago, IL: ASCP Press 1991: p. 113-68.

[8] Markal N, Kurtay A, Velidedeoglu H, et al. Malignant transformation of a giant proliferating trichilemmal tumor of the scalp: patient report and literature review. Ann Plast Surg 1998;41:314-6.

[9] Weiss J, Heine $M$, Grimmel $M$, et al. Malignant proliferating trichilemmal cyst. J Am Acad Dermatol 1995;32(5 Pt 2):870-3.

[10] Saida T, Oohara K, Hori Y, et al. Development of a malignant proliferating trichilemmal cyst in a patient with multiple trichilemmal cysts. Dermatologica 1983;166(4):203-8. 